\title{
Involvement of IGF-1/LARG Signaling in the Differentiation of Neural Stem Cells into Oligodendrocytes
}

\author{
Nobuchika Suzuki, Reiko Tokita and Shiro Minami \\ Department of Bioregulation, Nippon Medical School
}

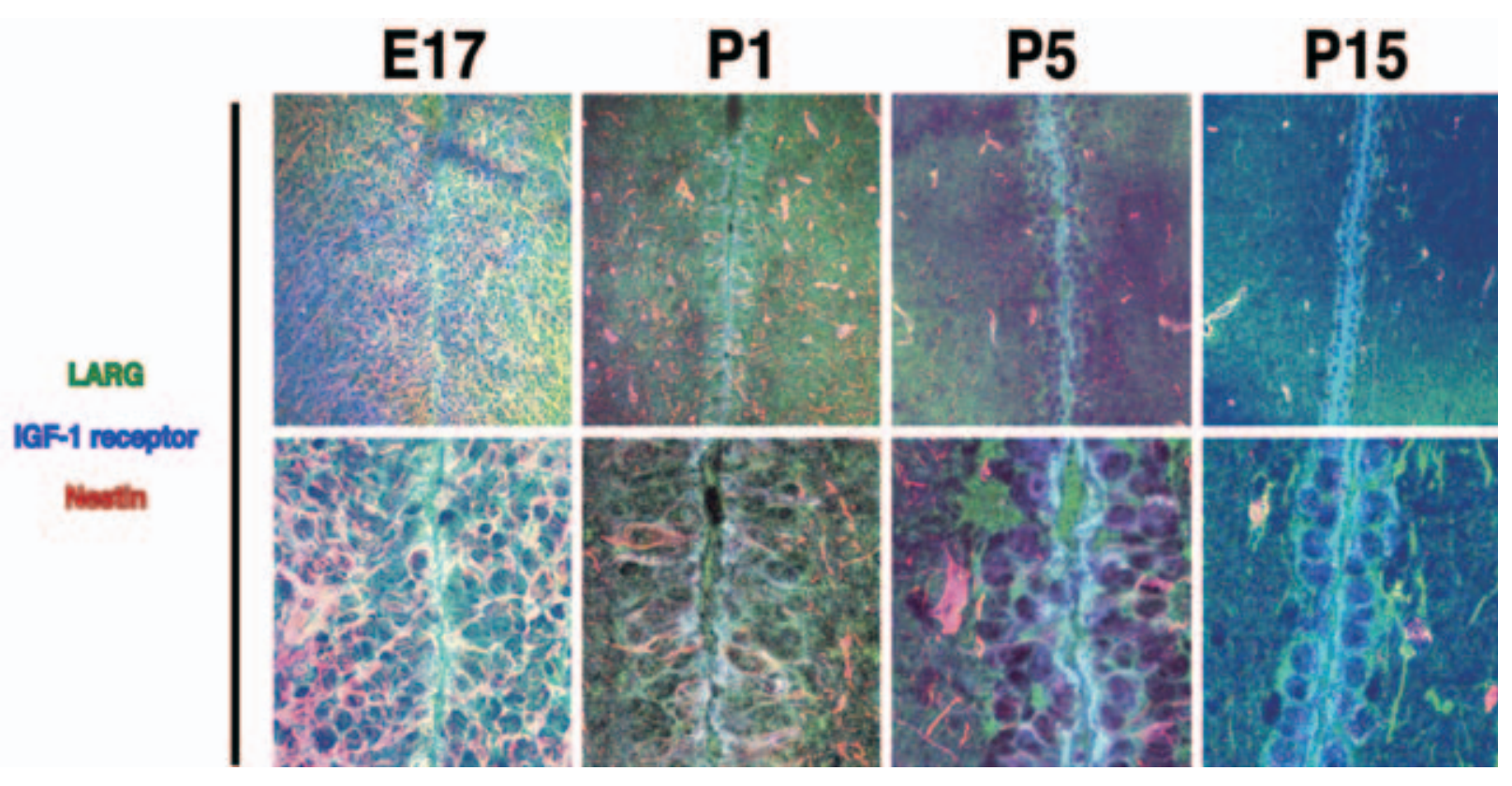

Fig. 1a

\begin{abstract}
Neural stem cells can differentiate into neurons, astrocytes, and oligodendrocytes in the mammalian central nervous system, but the molecular mechanisms that regulate the differentiation are not yet well understood. Insulin-like growth factor 1 (IGF-1) plays important roles during neuronal development. We examined the possibility that the IGF-1/leukemia-associated RhoGEF (LARG) pathway affects the differentiation of neural stem cells into oligodendrocytes. Characterization of cells positive for both IGF-1 receptor $\beta$ and LARG in the subventricular zone during neuronal development suggests that IGF-1/LARG signaling is involved in oligodendrocyte differentiation from multipotent neural progenitor cells.
\end{abstract}

Correspondence to Nobuchika Suzuki, Department of Bioregulation, Institute of Gerontology, Nippon Medical School, 1-396 Kosugi-cho, Nakahara-ku, Kawasaki, Kanagawa 211-8533, Japan 


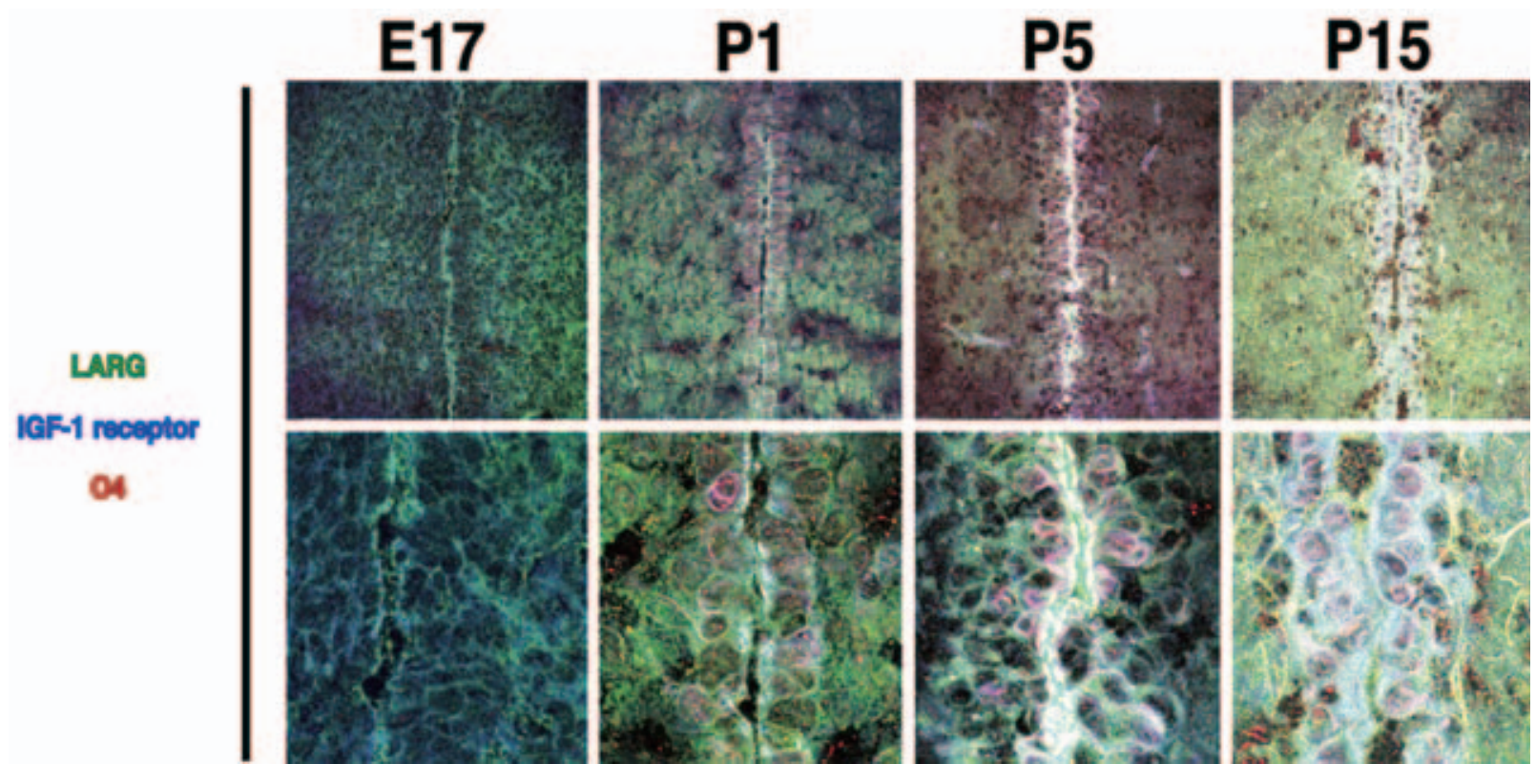

Fig. $1 b$

Fig. 1 Characterization of cells positive for both IGF-1 receptor $\beta$ and LARG in the subventricular zone during neuronal development. Brain sections from rats from embryonic day 17 (E17) to postnatal day 15 (P15) were triple-labeled with antibodies to IGF-1 receptor $\beta$, LARG, and a neural stem cell marker, Nestin, or an oligodendrocyte marker, O4. Merged images of sections focusing on the periventricular region are shown; IGF-1 receptor $\beta$ is in blue, LARG is in green, and Nestin or O4 is in red. Lower-magnification views (top panels) and higher-magnification views (bottom panels) are presented for each experiment. Bar, $100 \mu \mathrm{m}$.

E-mail: nobuchi@nms.ac.jpＪournal Website (http://www.nms.ac.jp/jnms/) 